\title{
La silueta de un maestro
}

\author{
EL DOCTOR D. GARCIA GUERRERO
}

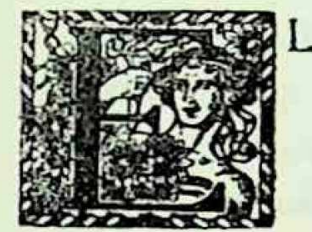

L Profesor Daniel Garcia Guerrero se ha retirado de la enseñanza en la plenitud de sus facultades, doblado apenas el cabo de la cincuentena, en esa edad en que discretas canas anuncian una aun lejana vejez y una recién perdida juventud.

Es la edad de las realidades, porque la experiencia ha dado el sentido de adivinar y de realizar las posibilidades. Con razón. los que se interesan por nuestra Escuela de Medicina, ven con pena su alejamiento: parte demasiado temprano. pero también más tarde. siempre su partida habría sido temprana.

Pocos profesores consiguen rodear su nombre de un nimbo de prestigio. ante el cual. cada uno en su fuero interno. rinde acato sin reticencia y sin menoscabo. como se rinde ante el nombre de García Guerrero. ¿Por qué? Porque este prestigio nace de la valia espiritual. Y ¿qué son ante la valia personal. el prestigio de la fortuna, o de la posición social. o de los honores, es decir. el prestigio fundado únicamente en condiciones extrinsecas a la personalidad humana?. son resplandores fatuos. pobres luminarias que sólo ofuscan a mentes cortesanas. El brillo de la valia espiritual es resplandor que irradia la propia personalidad. es luminosidad legitima y perenne. como es la del legitimo diamante.

García Guerrero adquirió y conservó ese prestigio que muchos ambicionan. que algunos ingenuos creen poseer y que pocos, poquisimos, alcanzan en verdad -viviendo oculto casi. sin escribir. sin hablar. pasando al margen de la vida social. en un retiro solitario que alegraba la lectura. la música y que lecundaba la meditación.

En los ratos de descanso. de abandono. se entregaba con toda su alma a la interpretación de Chopin, de Schumann... y la música evocadora lo hacia olvidar a los hombres con sus imperfecciones, a la tierra con sus tristes realidades.

A altas horas de la noche, cuando todo era silencio en el barrio colonial. cuando poco a poco se hundía en el olvido esa vida mediocre de los seres que 
sólo miran la tierra. García Guerrero lanzaba como un huracán de armonias. una sonata o una rapsodia, por la triste calle Riquelme... y la calle se estremecia. y muchos de sus habitantes salian del letargo y todos soñaban un instante:... pero luego, con gesto de gente que no comprende y que jamás comprenderá. decían: -jah! es ese doctor músico, Y el doctor músico todas las noches conversaba con almas selectas y las notas de su piano hacian pasearse sombras ilustres por las angostas veredas de la osbcura calle Riquelme, que tampoco comprendía y que jamás comprendió.

Asi unas veces se veía a una sombra alta, de andar pausado y majestuoso. envuelta en una amplia capa, una boina vasca sobre su fuerte nariz aguileña... Era Wagner.

Otras veces pasaba un espiritu con sotana. un viejo. de cabeza potente. afeitado. la cara llena de verrugas.... ¿era el ánima de un cura de aldea. de un ser bonachón y vulgar?... Nó, era Liszt.

Ciertas noches iba y volvia por la callejuela, con ademán afiebrado, un ser extraño. Su marcha era agitada; por momentos apresurado, se detenia bruscamente y permanecia largo tiempo inmóvil. la cabellera al viento. los ojos perdidos en el infinito. Parecía sostener un nunca interrumpido soliloquio. parecía que su alma era devastada por una continua tempestad... Era Beethoven.

Hoy el doctor músico habita frenle al mar, en lo alto de un barranco: sus amigos extra-terrenos, sin duda, le habrán escogido esta nueva morada.

García Guerrero abandonaba la soledad para subir a la cátedra. que lo transformaba. Habia nacido para hacer vida meramente espiritual.

En la música desahogaba toda su vida afectiva, en la cátedra toda su vida intelectual: en la una aparecia el ser sentimental en la otra el ser pensante.

La una y la otra se completaban. La música y la ciencia formaban como un jardin suspendido sobre el valle humano, y a ese valle obscuro Garcia Guerrero bajaba. obligado por las necesidades de la vida y se atardaba lo menos posible en él.

Por eso el ejercicio profesional jamás lo cautivó y por eso también no tuvo grandes ambiciones. Vivía en un plano en que sus ambiciones estaban satislechas.

Garcia Guerrero hubiera deseado ser un monje. pero un monje laico y habitar un convento, en medio de un bosque. en la cumbre de un cerro, un convento sin capilla, pero con anfiteatros. con laboratorios. poblado no de pecadores, sino de enfermos, pero de enfermos interesantes.

Hubiera deseado ser un monje y haber tenido por vecinos de celda, no a obispos, a cardenales, a políticos, a poderosos, sino a artistas, a escritores. a pintores, y con ellos haber tenido largas pláticas filosóficas, paseando bajo arcadas de apacibles corredores a bajo la sombra de las encinas como en el buen tiempo de Aristóteles.

Habia nacido para hacer una vida meramente espiritual. Su placer era el trabajo mental. Resolver un problema clínico por el placer de resolverlo, he aqui un goce que hacía poner en tensión todas sus facultades. 
A la observación esmerada del enfermo seguian procesos de inducción, de deducción. que se encadenaban en anillos apretados y que con una lógica meridiana terminaban en el diagnóstico. lleno de precisión. de minucia. de elegancia.

Un día después de largos estudios y de detenidos considerandos diagnosticó un cálculo en el conducto hepático derecho. El Prolesor Sierra operó y maravillado extrajo un cálculo del conducto hepático derecho.

Cada enfermo era un problema y cada problema un juego sutil del espiritu.

La verdad estaba prendida al fin de un hilo que en vueltas y revueltas formaba un ovillo. La cuestión era, en el ovillo, descubrir la punta del hilo y. poco a poco. desenrollarlo y dar al fin sin apuro. sin brusquedad, con la chispa en que remataba.

En su clase hacía experimentar al auditorio todas las sensaciones delicadas de ese trabajo finísimo. en que el espíritu vacilante. entre la verdad y el error. caminaba a la orilla de un precipicio, por un sendero que era fácil perder y que era el único que conducía a la meta.

Hablaba poco. contadas palabras. y era elocuente, porque es elocuente quien sabe hacer sentir la emoción, y los que lo escuchábamos nos emocionábamos al oirlo.

Sentado, ceñido en su correcto delantal blanco, asistía mudo al examen del enfermo. mudo, pero sus ojos brillaban y cuando aparecía un sintoma que él estimaba decidor. sus ojos miraban a sus alumnos y sonreian y entonces decia dos o tres palabras y estas palabras proyectaban viva luz en las sombras del misterio orgánico que tratábamos de descubrir.

Teniamos ante nosotros una negra cortina, que a su palabra como si se hubiera apoyado sobre un botón eléctrico. se descorria y dejaba a la vista hermosa perspectiva.

Y asi pasábamos de sensación en sensación hasła que aparecía el diagnóstico con la fuerza aplastante de la realidad, que no se discute porque se ve. porque se toca. porque cae bajo los sentidos.

Para llegar a él ponía en práctica lo que él llamaba la jerarquia de los sintomas. Una enfermedad determinada desencadena un grupo de sintomas. un sindrome. que en el libro aparecen en el mismo plano. En la naturaleza. las anormalidades anatómicas o fisiológicas, que no otra cosa son los sintomas, se presentan en orden disperso. unos acentuados, otros apagados y otros ocultos. Es necesario ir a buscarlos uno a uno y después de encontrarlos, es preciso saberle dar a cada uno la importancia que tiene en el conjunto sintomático y muchas veces de la importancia que se da a éste o aquél. surge este o aquel diagnóstico.

Al acentuar una u ofra nota. Garcia Guerrero procedia con el arte con que procede el pianista de talento, que insufla sobre toda la música que interpreta un sentimiento personal.

García Guerrero convirtió la Medicina, entre nosotros, en un arte.

La clase terminaba con una concisa disertación que el caso en estudio 
sugeria y que se apoyaba en la Anatomia. Fisiologia. Histologia normales y patológicas, que se apoyaba en los fundamentos de la Clínica. sin los cuales la Clinica es una ciencia superficial. empirica. caprichosa, sin la cual es una pseudo-ciencia.

La lección clinica dejaba de ser para García Guerrero una exposición académica, un discurso que tomaba como pretexto al enfermo, dejaba de ser una cosa ficticia y amanerada para convertirse en una exposición viva. llena de imprevistos y sujeta extrictamente a la verdad, y la verdad era el enfermo.

No buscaba el brillo en la palabra, obtenia el brillo sin quererlo en el tema mismo. No era elocuencia verbal, era la elocuencia de los hechos.

El se limitaba a traducir la naturaleza, tradutfore y no tradiftore, se colocaba a la orilla del marco y explicaba las bellezas del cuadro sin interponerse entre el paisaje y el espectador.

Tenia el don de hacer pensar. insinuaba la idea, imprimia el primer movimiento y después su mano se ocultaba. Era la escuela opuesta de aquella en que el profesor es un primer actor. que lo hace $y$ lo dice todo $y$ en el que el estudiante, ahorrando todo esfuerzo mental. se deja llevar como una barca por la corriente.

He aqui el gran mérito de Garcia Guerrero como pedagogo, enseñaba a pensar. enseñaba a discurrir y eso es el supremo objetivo didáctico, pero tal objetivo sólo lo pueden alcanzar los profesores que tienen vida espirifual propia. que piensan hondamente, que sienten fuertemente lo pensado. A estos profesores y sólo a éstos debe coronárseles con el titulo de maestros.

Garcia Guerrero era un maestro, y como maestro ha dejado discipulos. Hoy dia la enseñanza de la Medicina Interna en nuestra Escuela es la continuación directa de su enseñanza. Los tres profesores del ramo. Prado Tagle. Brockman y González Cortés. se formaron a su lado. fueron sus discipulos y alrededor de esos discipulos se están incubando nuevas generaciones de maestros.

Sólo una inteligencia luerte tiene el poder de seguir indicando rumbos aunque esté ausente, de seguir haciendo sentir su influencia al través del tiempo y del espacio. Sólo un objeto sólido y consistente provoca en la superficie del agua una serie de ondas que se extienden y se agrandan más y más; la pluma por muy hermoso que sea su color. la hoja seca por muy doradas que sean sus tonalidades descansan sobre la superficie del lago sin alterar la tersura de su espejo ni la tranquilidad de su fondo.

Pero Garcia Guerrero ha influido en otras formas sobre la Medicina Chilena.

El introdujo aqui la exploración experimental, que ha entrado de lleno en la práctica, pero que al principio levantó resistencia.

Un viejo prolesor llamó un día a García Guerrero y le dió a entender que no parecian serios aquellos llamativos instrumentos que trataban de reemplazar al antiguo y probado método directo. 
Fué también el iniciador del Laboratorio aplicado a la Clínica, que ha hecho después tal fortuna que ha llegado a desnafuralizar su espírifu.

El dato proporcionado por el laboratorio es simplemente un dato, un síntoma más que debe agregarse a los otros recogidos por el examen clinico, pero este dato debe ser interpretado, vivificado por la mente del médico y después tomar la colocación que le corresponde en la jerarquia de los sintomas que forman el sindrome propio de la enfermedad.

El laboratorio aplicado con inteligencia es sin duda el gran progreso del último tercio de siglo de la Ciencia Médica.

Garcia Guerrero quitó a la Medicina la fantasia y reemplazó la fantasía por el estudio. Se olvidó aquello del aojo clinico. tan en boga hace 30 años y se aprendió a observar y a raciocinar.

García Guerrero imprimió un sello indeleble en la ciencia que enseñó e hizo con la Medicina en Chile lo que hizo Orrego Luco con la Neurología.

He aqui dos nombres que no podremos olvidar.

Orrego Luco y García Guerrero, uno literato. el otro artista, han marcado con hondo surco el campo científico que recorrieron y lo consiguieron, porque fueron idealistas, porque tuvieron fe e ilusiones y la ilusión, como la estrella de los reyes magos. indica la buena ruta en la jornada de la vida.

CARLOS CHARLIN CORREA.

Santiago, 23 de Noviembre de 1924. 